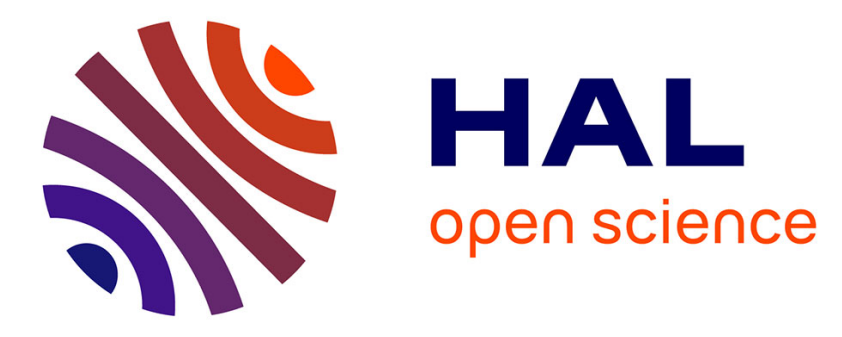

\title{
The association between alcohol consumption and mortality: the Swedish women's lifestyle and health study
}

Gundula Behrens, Michael F. Leitzmann, Sven Sandin, Marie Löf, Iris M. Heid, Hans-Olov Adami, Elisabete Weiderpass

\section{To cite this version:}

Gundula Behrens, Michael F. Leitzmann, Sven Sandin, Marie Löf, Iris M. Heid, et al.. The association between alcohol consumption and mortality: the Swedish women's lifestyle and health study. European Journal of Epidemiology, 2011, 26 (2), pp.81-90. 10.1007/s10654-011-9545-x . hal-00663076

\section{HAL Id: hal-00663076 https://hal.science/hal-00663076}

Submitted on 26 Jan 2012

HAL is a multi-disciplinary open access archive for the deposit and dissemination of scientific research documents, whether they are published or not. The documents may come from teaching and research institutions in France or abroad, or from public or private research centers.
L'archive ouverte pluridisciplinaire HAL, est destinée au dépôt et à la diffusion de documents scientifiques de niveau recherche, publiés ou non, émanant des établissements d'enseignement et de recherche français ou étrangers, des laboratoires publics ou privés. 


\section{Original Article:}

The association between alcohol consumption and mortality: the Swedish Women's

\section{Lifestyle and Health Study}

Gundula Behrens ${ }^{1}$, Michael F. Leitzmann ${ }^{1}$, Sven $\operatorname{Sandin}^{2}$, Marie Löf ${ }^{2}$, Iris M. Heid ${ }^{1}$, HansOlov Adami ${ }^{2,3}$, and Elisabete Weiderpass ${ }^{2,4,5}$

Author affiliations:

${ }^{1}$ Department of Epidemiology and Preventive Medicine, Regensburg University Medical Center, Franz-Josef-Strauss-Allee 11, 93053 Regensburg, Germany.

${ }^{2}$ Department of Medical Epidemiology and Biostatistics, Karolinska Institutet, P.O. Box 281, Nobels väg 12 A, SE-171 77 Stockholm, Sweden.

${ }^{3}$ Department of Epidemiology, Harvard School of Public Health, 677 Huntington Avenue, Boston, MA 02115, USA.

${ }^{4}$ Cancer Registry of Norway, Oslo, and Department of Community Medicine, Tromso, Norway.

${ }^{5}$ Program on Genetic Research, Folkhälsan Research Center

Biomedicum 1, Haartmansgatan 8, PB 63 (C321b), FI-00014 University of Helsinki, Helsinki, Finland.

Corresponding author and reprint requests: Dr. Gundula Behrens, Department of Epidemiology and Preventive Medicine, Regensburg University Medical Center Franz-Josef-Strauss-Allee 11, 93053 Regensburg, Germany (email: gundula.behrens@klinik.uni-regensburg.de; Tel.: +49-941-944-5217; Fax: +49-941-9445202). 
Running head: Alcohol and mortality in women

Word count: 206 (abstract); 3,458 (text)

Key words: Alcohol, mortality, women's health, cohort study 


\begin{abstract}
Although light to moderate alcohol intake may reduce cardiovascular disease (CVD) mortality, the effect on total mortality requires further study, particularly among young and middle-aged women. We studied the association between alcohol consumption and mortality from all causes, from cancer, and from CVD in the Swedish Women's Lifestyle and Health Study, a cohort of 47,921 female residents of Sweden aged 30 to 49 years at baseline in 1991/1992 and followed up to 2006. We estimated the relative risk (RR) of mortality associated with alcohol intake using Cox regression adjusted for age, smoking, BMI, saturated fat intake, physical activity, and education. During 713,295 person-years of followup, 1,119 deaths occurred, including 158 deaths from CVD, 673 deaths from cancer, and 288 deaths from other causes. Compared with non-drinking, light to moderate drinking (0.1-19.9 grams of alcohol per day) showed a statistically significant inverse association with total mortality $(\mathrm{RR}=0.83,95 \% \mathrm{CI}=0.71-0.98)$. Analyses of cause-specific mortality revealed an $\mathrm{RR}$ for CVD mortality of 0.69 (95\% CI=0.46-1.01) and an RR for cancer mortality of $0.92(95 \%$ $\mathrm{CI}=0.75-1.15)$. These results suggest that in younger women, a possibly beneficial effect of light to moderate drinking on future risk of mortality is limited to a prevention of CVD mortality but not cancer mortality.
\end{abstract}




\section{Introduction}

Alcohol consumption plays an important role in numerous cultures, in particular in Western societies. The adverse effects of excessive alcohol consumption on health and mortality are well established (1). It is also widely believed that modest alcohol consumption is beneficial to health (1). However, the effects of alcohol on health may differ according to sex, age, and ethnicity (1-3). In addition, there has been concern about potential bias due to the mutual inclusion of lifetime abstainers, former heavy drinkers, and those who stopped consuming alcohol due to poor health into a single reference group of non-drinkers $(2,4,5)$. A further concern is that light to moderate alcohol drinking may reduce risk of mortality from cardiovascular disease (CVD), in particular mortality from coronary heart disease (CHD) (6, $7)$, but that even modest intake of alcohol may adversely affect cancer mortality $(8,9)$. To further explore these issues, we examined the association between alcohol intake and mortality from any cause, CVD mortality, and cancer mortality in the Swedish Women's Lifestyle and Health Study with nearly 50,000 women living in Sweden. The cohort includes a large number of light to moderate drinkers, a level of alcohol intake that is considered controversial in terms of its potential health benefits. Furthermore, the cohort's baseline age range of 30 to 49 years is exceptional: previous studies have looked either at a much broader age range (9-11) or at older women $(12,13)$.

\section{Methods}

\section{The cohort}

The Women's Lifestyle and Health (WLH) cohort is a prospective study of women that was approved by the Ethical Committee of the Karolinska Institute Stochholm and then initiated between August 1991 and June 1992 in the Uppsala Health Care Region, Sweden, when 96,000 female residents aged 30 to 49 years were randomly selected and posted a self-report 
questionnaire. Of these, 49,259 women gave their informed consent and were enrolled in the WLH study. A follow-up questionnaire was sent between February 2003 and January 2004, which a total of 34,402 women completed. Both questionnaires requested information regarding anthropometric measurements, personal history of diseases, smoking and drinking habits, diet, and physical activity.

\section{Assessment of alcohol intake}

On the baseline questionnaire, each woman was asked to report the number of glasses of beer $(1$ glass=2 dl $)$, wine $(1$ glass= $1 \mathrm{dl})$, and spirits $(1$ glass $=4 \mathrm{cl})$ that she currently drank per week, per month, or per year. The woman could also report that she never or seldom drank alcohol. The reported quantities of beer, wine and spirits were converted to grams of alcohol using food composition data from the Swedish National Food Administration (14). The follow-up questionnaire contained a corresponding question regarding alcohol intake although the frequencies and quantities were somewhat differently formulated. The reported quantities of beer, wine and spirits were converted into quantities of alcohol in the same manner as those from the baseline questionnaire.

\section{Analytic cohort}

For the current analysis, we excluded 484 women with incomplete baseline information on alcohol or total energy intake, 984 women with extreme energy intakes (top or bottom $1 \%$ of the energy intake distribution), and 10 women who completed the baseline questionnaire but were later found to have emigrated from Sweden immediately afterwards, which left 47,921 women for our main analysis. 


\section{Endpoint definition}

Cohort members were followed from August 1991 through December 31, 2006 by linking the cohort to the national registers (Death Register, Cancer Register, and Immigration Register) through their unique national registration numbers (15), making follow-up virtually complete $(16,17)$. Cases of mortality were identified by the International Classification of Diseases codes (ICD-9 and ICD-10). The primary endpoint for the present analysis was mortality from any cause. In secondary analyses, we considered mortality from cancer (ICD-9 140-209 or ICD-10 C00-D09), CVD (ICD-9 390-459 or ICD-10 I00-I99), and non-cancer/non-CVD causes (ICD-9 001-139, 210-389, 460-999 or ICD-10 A00-B99, D10-H95, J00-Z99).

\section{Statistical main analysis}

Each study participant accrued follow-up time beginning at the date of return of the baseline questionnaire and ending at the date of death, emigration, or the end of follow-up in December 31, 2006, whichever occurred first. Following the Nurses' Health Study (18) as closely as the number of cases allowed, alcohol intake categories were defined as 0, 0.1-1.4, 1.5-4.9, 5.0-9.9, 10.0-14.9, and 15.0+ grams of alcohol per day. For example, the category of 1.5-4.9 grams of alcohol per day corresponds to approximately two glasses of wine per week $(1$ glass $=1 \mathrm{dl}$; alcohol by volume $=10 \%)$. To further facilitate comparison with previous studies, we also compared subjects with 0.1-19.9 grams of alcohol per day with subjects with no alcohol consumption $(11,19-21)$ as well as participants consuming any quantity of alcohol with non-drinkers $(12,13,22)$. We fitted Cox proportional hazards regression models to estimate the relative risks of mortality associated with alcohol intake. We verified that the assumption of proportional hazards was not violated using Schoenfeld residuals (23). 
For age-adjusted analyses, we used five-year age groups at baseline. In multivariable models, we additionally adjusted for body mass index (BMI) $\left(<18.5,18.5-24.9,25.0+\mathrm{kg} / \mathrm{m}^{2}\right)$, energyadjusted (24) saturated fat intake (grams per day in quintiles), smoking status (never, past, and current smoking with current intensities of 1-14, 15-24, 25+ cigarettes per day), level of physical activity [derived from the original self-assessment scale of 1 through 5 (very low to very high level of physical activity, considering both working and leisure time) as low (1 or $2)$, intermediate (3), or high (4 or 5)], and education level $(0-10,11-13,14+$ years). For tests of linear trend across categories of alcohol intake, we assigned each categorical alcohol value the median alcohol intake within that category and determined the $\mathrm{P}$ value of the resulting continuous variable using the Wald test.

All relative risks (RRs) are presented with 95\% confidence intervals $(\mathrm{CI})$, and reported $\mathrm{P}$ values are based on two-sided tests at the 5\% significance level. All analyses were conducted using the statistical software SAS release 9.2 (SAS Institute, Cary, NC).

\section{Statistical sub-analyses}

Firstly, to assess potential bias by preclinical chronic disease, we repeated the analysis excluding all women with pre-existing hypertension, type 2 diabetes mellitus, or cancer and additionally excluded the first two years of follow-up for all women. Secondly, to investigate consistent drinking patterns we used data on consistent drinking versus consistent alcohol avoidance from both the baseline and the 2003 follow-up questionnaires, restricting the analysis to deaths that occurred between 2003 and 2006. Thirdly, we addressed potential confounding due to including past heavy drinkers in the reference group of non-drinkers by excluding non-drinkers in 2003 who had previously reported alcohol intake of 10 grams per day or more in 1991/1992. Fourthly, to examine whether the association of alcohol to 
mortality was modified by other risk factors for mortality, we conducted tests for multiplicative interaction using likelihood-ratio tests. We also evaluated the relation of alcohol to mortality within strata of potential effect modifying variables. Fifthly, we performed mortality type specific analyses analogously to the all-cause mortality investigations.

Finally, we conducted beverage type specific analyses for wine, beer and spirits, classified as $0,0.1-1.4,1.5-4.9$, or 5.0+ grams per day. These analyses were mutually adjusted for alcohol intake from other beverage types, e.g. the wine analysis was adjusted for beer and spirits intakes.

\section{Results}

\section{Distribution of events and alcohol intake}

During 713,295 person-years of follow-up between 1991 and 2006, a total of 1,119 deaths occurred, including 673 deaths from cancer (184 from breast cancer, 122 from cancers of the trachea, bronchus, and lung, and 60 from ovarian cancer), 158 from CVD (69 from CHD, 12 from stroke, and 77 from other CVD-related causes), 54 deaths from injury or poisoning, 39 deaths from suicide, and 195 deaths from other causes. Censoring events were distributed between 7 days and 15.3 years after study entry, with a mean censoring time of 15.0 years. Deaths occurred between 68 days and 15.3 years after study entry with a mean of time to death of 9.2 years. Thirty subjects died and 79 subjects were censored within one year of entry. The mean ages at baseline and at the end of follow-up were 39.2 years and 54.3 years, respectively. 
Of the 47,921 women in our analytic cohort, $13.4 \%$ declared no alcohol intake, the majority of women $(84.5 \%)$ reported alcohol intakes of 0.1 to 14.9 grams per day, and $2.1 \%$ of participants stated an average daily alcohol intake of 15 grams or more at baseline. The vast majority (over 99\%) of women consumed less than 20 grams of alcohol per day. In the intake groups of 0, 0.1-1.4, 1.5-4.9, 5.0-9.9, and 10.0-14.9 grams of alcohol per day, deaths were mainly attributed to breast cancer (14-19\% of all deaths) or to cancers of the trachea, bronchus or lung (9-13\%). By comparison, in the highest intake group of $15.0+$ grams of alcohol or more per day, the top two causes of mortality were injury/poisoning (12\%) and breast cancer $(8 \%)$. The correlation coefficient between wine and beer intake was 0.11 , between wine and spirits intake it was 0.15 , and between beer and spirits intake it was 0.16 , implying that study participants showed no strong preference for the combination of any two alcoholic beverage types.

\section{Distribution of risk factors at baseline}

We present summary statistics of potentially confounding factors by categories of total alcohol intake (Table 1). With increasing total alcohol intake, women were more likely to be past or current smokers, which would tend to increase the risk of mortality. On the other hand, women with greater total alcohol consumption were better educated, they showed less saturated fat intake, and they were less likely to have been diagnosed with diabetes than women who abstained from alcohol, a risk factor profile that would tend to decrease risk of mortality. Physical activity, which also tends to decrease mortality risk, was highest among women in the intermediate alcohol categories between 1.5 and 14.9 grams per day. BMI and history of hypertension did not vary appreciably according to alcohol intake. Corresponding figures for baseline characteristics by specific alcoholic beverage types can be found in the (web-based) Supplementary Table 1. 


\section{All-cause mortality}

We investigated the relation of total alcohol intake to all-cause mortality using the zero intake group as reference (Fig. 1). In multivariable analyses, we inspected the mortality risk in the intake groups $0.1-1.4,1.5-4.9,5.0-9.9,10.0-14.9$, and $15.0+$ grams of alcohol per day compared to alcohol abstinence and found null associations for all levels with the exception of one category: for 1.5-4.9 grams of alcohol per day the association proved to be statistically significant and inverse $(\mathrm{RR}=0.81,95 \% \mathrm{CI}=0.67-0.97)$. Statistically significant inverse associations were also found for the larger group of 0.1-19.9 grams of alcohol intake per day $(\mathrm{RR}=0.83,95 \% \mathrm{CI}=0.71-0.98)$ versus none, and for any versus no alcohol intake $(\mathrm{RR}=0.84$, 95\%=0.71-0.98). Adjusting for hypertension status and diabetes status did not appreciably affect the results (data not shown). Excluding women with a history of hypertension, type 2 diabetes mellitus, or cancer at baseline and excluding the first two years of follow-up did not essentially alter the results (data not shown). In 2003, 10.3\% of women were non-drinkers, $80.7 \%$ of women stated an alcohol intake of 0.1 to 14.9 grams per day, and $9.0 \%$ of women consumed over 15 grams of alcohol per day. Over 95\% of women reported an alcohol intake less than 20 grams of alcohol per day in 2003. Age-adjusted analyses revealed that women consistently reporting alcohol use in 1991/1992 and in 2003 had a statistically significant lower mortality risk between 2003 and 2006 than consistent non-drinkers (RR=0.64, 95\% $\mathrm{CI}=0.41-1.00)$. Exclusion of potential former heavy drinkers from the non-drinking group did not alter those results.

\section{Cause-specific mortality}

We examined the relation between alcohol intake and mortality from specific causes (Table 2). In analyses adjusted for potential confounding factors, we observed an RR for CVD 
mortality of 0.69 (95\% CI=0.46-1.01) comparing an alcohol intake of 0.1-19.9 grams per day with no alcohol intake and an RR for cancer mortality of $0.92(95 \% \mathrm{CI}=0.75-1.15)$ comparing an alcohol intake of 0.1-19.9 grams per day with no alcohol intake.

\section{Analyses within strata of mortality risk factors}

In multivariable analyses, we looked at associations between alcohol and mortality within strata of other risk factors (Table 3). In women aged 30 to 34 years at baseline, the highest intake group of 15 grams of alcohol per day or more revealed a statistically significant increase in total mortality risk $(\mathrm{RR}=3.11,95 \% \mathrm{CI}=1.18-8.20)$ compared to no alcohol intake, while the intermediate intake levels showed null associations. In contrast, among women aged 35 to 49 years at baseline the highest intake group of more than 15 grams of alcohol per day showed the strongest, statistically significant risk reduction $(\mathrm{RR}=0.55,95 \% \mathrm{CI}=0.34-0.90)$ compared to non-drinkers. In that age group, intake levels 0.1-1.4 grams of alcohol per day $(\mathrm{RR}=0.81,95 \% \mathrm{CI}=0.67-0.99)$ and 1.5-4.9 grams of alcohol per day $(\mathrm{RR}=0.76,95 \% \mathrm{CI}=0.63-$ 0.92) were statistically significantly and inversely associated with mortality (P value for interaction by age $=0.047$ ). The association between alcohol and mortality did not vary across strata defined by BMI, saturated fat intake, smoking, history of hypertension, type 2 diabetes mellitus, physical activity, or education (data not shown).

\section{Specific alcoholic beverage types}

We also performed analyses by specific alcoholic beverage type (Table 4). The only statistically significant results from the multivariable analyses were as follows: compared to zero beer intake, 0.1-1.4 grams of alcohol per day from beer intake $(\mathrm{RR}=0.83,95 \% \mathrm{CI}=0.72$ 0.96) and 1.5-4.9 grams of alcohol per day from beer intake (RR=0.83, 95\% $\mathrm{CI}=0.70-0.98)$ were inversely associated with total mortality. In contrast, we noted a statistically significant 
positive association for women with an average daily alcohol from spirits intake of 5 grams or more $(\mathrm{RR}=1.52,95 \% \mathrm{CI}=1.04-2.22$, $\mathrm{p}$-trend=0.05).

\section{Discussion}

In this cohort of mostly light to moderate drinking women aged 30 to 49 years at baseline compared to non-drinkers, we observed an approximately 20 to $30 \%$ apparent reduction in mortality risk for various categories of alcohol intake within the range of 1.5 to 20 grams per day, with an overall $16 \%$ reduction in risk for mortality when we compared women with any versus no alcohol intake. We were unable to assess the association with alcohol intake beyond 20 grams per day because of insufficient numbers of women (1\% of women in our cohort).

A study from England and Wales revealed that as age increases, the level of alcohol intake associated with maximal risk reduction increases as well, suggesting that results from cohorts with different age distributions cannot be strictly compared (3). The study most closely related to ours with respect to its age and sex structure and alcohol and mortality results is the Nurses' Health Study with an analytic sample of 86,000 women aged 35 to 59 years at baseline (18). That study revealed a statistically significant inverse relation of alcohol intake to mortality for an intake range of 1.5 to 14.9 grams per day (RR for 1.5 to 4.9 grams per day $=0.83 ; 95 \% \mathrm{CI}=0.74-0.93$; RR for 5.0 to 14.9 grams per day $=0.88 ; 95 \% \mathrm{CI}=0.79-0.99$ ) with estimates similar to ours. Studies with wider age ranges than ours or with partly overlapping age structures also detected statistically significant inverse $(9-11,25,26)$ or null (19-21) associations between alcohol intakes of up to 20 grams per day and all-cause mortality. Studies in women over age 50 years also found statistically significant mortality risk reductions associated with any versus no alcohol intake $(12,13)$. One combined analysis in men and women over age 50 years confirmed a statistically significant risk reduction for 
any versus no alcohol intake (22), another detected statistically significant risk reductions for alcohol intakes of up to 28 grams per day only (27).

In the youngest women in our cohort, i.e., in those aged 30 to 34 years at baseline, alcohol intake of 15 grams or more per day was associated with increased mortality risk, whereas in women aged 35 years or older at baseline alcohol consumption of 15 grams per day of alcohol or more was related to decreased mortality risk. The Nurses' Health Study also found that for any given level of alcohol intake, the apparent adverse effect of alcohol on risk for mortality was consistently more pronounced among younger than older women (18), ranging from $\mathrm{RR}=2.46(95 \% \mathrm{CI}=0.50-12.4)$ for women aged 34 to 39 years to $\mathrm{RR}=1.02(95 \% \mathrm{CI}=0.80$ 1.30) for women over 60. Similar conclusions were reached by the Japanese Collaborative Cohort Study $(11,28)$ and the National Health Epidemiology Follow-up Study $(11,28)$.

In our study, a null association was observed between alcohol consumption and cancer mortality. Similarly, the Nurses' Health Study detected a null association for cancer mortality with alcohol intake up to 30 grams per day $(18,29)$. A modest positive association was observed for intake levels of 30 grams per day or more in the Nurses' Health Study $(18,29)$. Other studies showed statistically significant positive $(4,8,9)$ or null $(11)$ associations between alcohol and cancer mortality in women or in men and women combined (30).

We noted an inverse association between low alcohol intake (1.5 to 4.9 grams and 0.1-19.9 grams of alcohol per day) and mortality from CVD. The Nurses' Health Study observed statistically significant decreased risks of CVD mortality with 1.5 to 4.9 grams $(\mathrm{RR}=0.57$; $95 \% \mathrm{CI}=0.43-0.76), 5.0$ to 14.9 grams $(\mathrm{RR}=0.73 ; 95 \% \mathrm{CI}=0.56-0.95)$, and 15.0 to 29.9 $(\mathrm{RR}=0.66 ; 95 \% \mathrm{CI}=0.47-0.93)$ grams of alcohol intake per day $(18,29)$. Other studies also 
revealed inverse relations between alcohol intake and CVD (or CHD) mortality in women (9, $25,31,32)$ or in men and women combined $(22,30)$. Non-linear inverse associations for low alcohol intakes and positive $(33)$ or null $(4,7,8,10)$ associations for higher alcohol intakes were also identified in numerous studies among women.

Similar to our study, most other studies found an inverse association between beer consumption and mortality in women $(12,13,34)$ or in men and women combined $(30,32)$. Only few studies reported a positive relation of beer to mortality $(20,35)$. Inverse associations between wine intake and mortality risk were noted in studies among women (4, 12, 20, 34, $35)$ or in analyses involving both women and men $(30,32)$. We observed a positive association between spirits intake and risk of mortality. Previous studies reported inverse (12), null $(20,34)$, or positive (35) relations between spirits intake and mortality risk. Previous analyses combining men and women showed null $(32)$ or positive $(30,36)$ associations.

One of our study's strengths is its particular age and sex structure of younger women. Further merits are that potential recall bias was precluded by the prospective study design, potential information bias was minimized by the reasonably valid and reliable food frequency questionnaire comparable to that used in a similar study (37), and potential selection bias was avoided by the virtually complete follow-up. In addition, we minimised the potential for confounding by controlling for numerous accepted risk factors for mortality. Since previous studies reported both greater $(2,4,5,26,35,38,39)$ or lower mortality risk $(11,20)$ among female former drinkers compared to female lifetime abstainers, we were concerned with potential bias through the inclusion of ill former heavy drinkers in the reference group, but found that the exclusion of former drinkers did not alter our results. Our study had limited 
power to explore associations with specific causes of mortality and mortality among women with alcohol intakes with over 20 grams per day.

Moderate intake of ethanol could prevent CVD by numerous biological mechanisms, such as improving endothelial function, lowering blood pressure, reducing inflammation, increasing high density lipoprotein (HDL) cholesterol and decreasing low density lipoprotein (LDL) cholesterol, enhancing fibrinolysis, inhibiting platelet aggregation and coagulation, attenuating insulin resistance, and releasing stress $(6,40,41)$. In addition to ethanol, other components of alcoholic beverages, thus as flavonoids and resveratrol, prevent CVD in ways similar to ethanol (6). An open issue is whether the apparent benefit of ethanol for vascular health depends on alcoholic beverage type. A meta-analysis reported inverse relations of both wine and beer intake to CVD risk that was greater for wine than for beer intake (42). Divergent beverage type-specific results might arise due to residual confounding by sociodemographic or lifestyle factors; the greatest risk reductions were typically observed for the alcoholic beverage type predominantly consumed in the specific population under study $(4,43)$.

In conclusion, we observed a moderate reduction in total and CVD mortality but not in cancer mortality among women with any versus no alcohol intake. These results, broadly consistent with findings from previous studies, suggest a beneficial effect of light to moderate drinking on women's health. Despite the apparent benefits of moderate alcohol intake for mortality risk, health care providers should discuss the potential hazards of alcohol consumption with their patients and provide them with an individual clinical recommendation. 


\section{Acknowledgments}

We thank Pouran Almstedt for excellent data management.

\section{References}

1. Di Castelnuovo A, Costanzo S, Bagnardi V, Donati MB, Iacoviello L, de Gaetano G. Alcohol dosing and total mortality in men and women: an updated meta-analysis of 34 prospective studies. Arch Intern Med. 2006 Dec 11-25;166(22):2437-45.

2. Nakaya N, Kurashima K, Yamaguchi J, Ohkubo T, Nishino Y, Tsubono Y, et al. Alcohol consumption and mortality in Japan: the Miyagi Cohort Study. J Epidemiol. 2004 Feb;14 Suppl 1:S18-25.

3. White IR, Altmann DR, Nanchahal K. Alcohol consumption and mortality: modelling risks for men and women at different ages. BMJ. 2002 Jul 27;325(7357):191.

4. Klatsky AL, Friedman GD, Armstrong MA, Kipp H. Wine, liquor, beer, and mortality. Am J Epidemiol. 2003 Sep 15;158(6):585-95.

5. Dawson DA. Alcohol consumption, alcohol dependence, and all-cause mortality. Alcohol Clin Exp Res. 2000 Jan;24(1):72-81.

6. Kloner RA, Rezkalla SH. To drink or not to drink? That is the question. Circulation. 2007 Sep 11;116(11):1306-17.

7. Ikehara S, Iso H, Toyoshima H, Date C, Yamamoto A, Kikuchi S, et al. Alcohol consumption and mortality from stroke and coronary heart disease among Japanese men and women: the Japan collaborative cohort study. Stroke. 2008 Nov;39(11):2936-42.

8. Breslow RA, Graubard BI. Prospective study of alcohol consumption in the United States: quantity, frequency, and cause-specific mortality. Alcohol Clin Exp Res. 2008 Mar;32(3):513-21. 
9. Thun MJ, Peto R, Lopez AD, Monaco JH, Henley SJ, Heath CW, Jr., et al. Alcohol consumption and mortality among middle-aged and elderly U.S. adults. N Engl J Med. 1997 Dec 11;337(24):1705-14.

10. Djousse L, Lee IM, Buring JE, Gaziano JM. Alcohol consumption and risk of cardiovascular disease and death in women: potential mediating mechanisms. Circulation. 2009 Jul 21;120(3):237-44.

11. Lin Y, Kikuchi S, Tamakoshi A, Wakai K, Kawamura T, Iso H, et al. Alcohol consumption and mortality among middle-aged and elderly Japanese men and women. Ann Epidemiol. 2005 Sep;15(8):590-7.

12. Paganini-Hill A, Kawas CH, Corrada MM. Type of alcohol consumed, changes in intake over time and mortality: the Leisure World Cohort Study. Age Ageing. 2007 Mar;36(2):203-9.

13. Simons LA, McCallum J, Friedlander Y, Ortiz M, Simons J. Moderate alcohol intake is associated with survival in the elderly: the Dubbo Study. Med J Aust. 2000 Aug 7;173(3):121-4.

14. National_Food_Administration. Food Composition Tables. Uppsala 1989.

15. Kumle M, Weiderpass E, Braaten T, Adami HO, Lund E. Risk for invasive and borderline epithelial ovarian neoplasias following use of hormonal contraceptives: the Norwegian-Swedish Women's Lifestyle and Health Cohort Study. Br J Cancer. 2004 Apr 5;90(7):1386-91.

16. Mattsson B, Wallgren A. Completeness of the Swedish Cancer Register. Non-notified cancer cases recorded on death certificates in 1978. Acta Radiol Oncol. 1984;23(5):305-13. 17. Lunde AS, Lundeborg S, Lettenstrom GS, Thygesen L, Huebner J. The person-number systems of Sweden, Norway, Denmark, and Israel. Vital Health Stat 2. 1980(84):1-59. 
18. Fuchs CS, Stampfer MJ, Colditz GA, Giovannucci EL, Manson JE, Kawachi I, et al. Alcohol consumption and mortality among women. N Engl J Med. 1995 May 11;332(19):1245-50.

19. Marugame T, Yamamoto S, Yoshimi I, Sobue T, Inoue M, Tsugane S, et al. Patterns of alcohol drinking and all-cause mortality: results from a large-scale population-based cohort study in Japan. Am J Epidemiol. 2007 May 1;165(9):1039-46.

20. Baglietto L, English DR, Hopper JL, Powles J, Giles GG. Average volume of alcohol consumed, type of beverage, drinking pattern and the risk of death from all causes. Alcohol Alcohol. 2006 Nov-Dec;41(6):664-71.

21. Hoffmeister H, Schelp FP, Mensink GB, Dietz E, Bohning D. The relationship between alcohol consumption, health indicators and mortality in the German population. Int J Epidemiol. 1999 Dec;28(6):1066-72.

22. Knoops KT, de Groot LC, Kromhout D, Perrin AE, Moreiras-Varela O, Menotti A, et al. Mediterranean diet, lifestyle factors, and 10-year mortality in elderly European men and women: the HALE project. JAMA. 2004 Sep 22;292(12):1433-9.

23. Schoenfeld DA. Partial residuals for the proportional hazards regression model. Biometrika. 1982;69(1):239-41.

24. Willett WC, Howe GR, Kushi LH. Adjustment for total energy intake in epidemiologic studies. Am J Clin Nutr. 1997 Apr;65(4 Suppl):1220S-8S; discussion 9S-31S. 25. Theobald H, Johansson SE, Bygren LO, Engfeldt P. The effects of alcohol consumption on mortality and morbidity: a 26-year follow-up study. J Stud Alcohol. 2001 Nov;62(6):783-9.

26. Liao Y, McGee DL, Cao G, Cooper RS. Alcohol intake and mortality: findings from the National Health Interview Surveys (1988 and 1990). Am J Epidemiol. 2000 Apr $1 ; 151(7): 651-9$. 
27. Gronbaek M, Deis A, Becker U, Hein HO, Schnohr P, Jensen G, et al. Alcohol and mortality: is there a U-shaped relation in elderly people? Age Ageing. 1998 Nov;27(6):73944.

28. Rehm J, Sempos CT. Alcohol consumption and all-cause mortality. Addiction. 1995 Apr;90(4):471-80.

29. van Dam RM, Li T, Spiegelman D, Franco OH, Hu FB. Combined impact of lifestyle factors on mortality: prospective cohort study in US women. BMJ. 2008;337:a1440.

30. Gronbaek M, Becker U, Johansen D, Gottschau A, Schnohr P, Hein HO, et al. Type of alcohol consumed and mortality from all causes, coronary heart disease, and cancer. Ann Intern Med. 2000 Sep 19;133(6):411-9.

31. Mukamal KJ, Chen CM, Rao SR, Breslow RA. Alcohol consumption and cardiovascular mortality among U.S. adults, 1987 to 2002. J Am Coll Cardiol. 2010 Mar 30;55(13):1328-35.

32. Klatsky AL, Armstrong MA, Friedman GD. Risk of cardiovascular mortality in alcohol drinkers, ex-drinkers and nondrinkers. Am J Cardiol. 1990 Nov 15;66(17):1237-42. 33. Rehm JT, Bondy SJ, Sempos CT, Vuong CV. Alcohol consumption and coronary heart disease morbidity and mortality. Am J Epidemiol. 1997 Sep 15;146(6):495-501.

34. Lapidus L, Bengtsson C, Bergfors E, Bjorkelund C, Spak F, Lissner L. Alcohol intake among women and its relationship to diabetes incidence and all-cause mortality: the 32-year follow-up of a population study of women in Gothenburg, Sweden. Diabetes Care. 2005 Sep;28(9):2230-5.

35. Harriss LR, English DR, Hopper JL, Powles J, Simpson JA, O'Dea K, et al. Alcohol consumption and cardiovascular mortality accounting for possible misclassification of intake: 11-year follow-up of the Melbourne Collaborative Cohort Study. Addiction. 2007 Oct;102(10):1574-85. 
36. Gronbaek M, Deis A, Sorensen TI, Becker U, Schnohr P, Jensen G. Mortality associated with moderate intakes of wine, beer, or spirits. BMJ. 1995 May 6;310(6988):11659.

37. Wolk A, Bergstrom R, Hunter D, Willett W, Ljung H, Holmberg L, et al. A prospective study of association of monounsaturated fat and other types of fat with risk of breast cancer. Arch Intern Med. 1998 Jan 12;158(1):41-5.

38. Freiberg MS, Chang YF, Kraemer KL, Robinson JG, Adams-Campbell LL, Kuller LL. Alcohol consumption, hypertension, and total mortality among women. Am J Hypertens. 2009 Nov;22(11):1212-8.

39. Cullen KJ, Knuiman MW, Ward NJ. Alcohol and mortality in Busselton, Western Australia. Am J Epidemiol. 1993 Jan 15;137(2):242-8.

40. Gronbaek M. The positive and negative health effects of alcohol- and the public health implications. J Intern Med. 2009 Apr;265(4):407-20.

41. O'Keefe JH, Bybee KA, Lavie CJ. Alcohol and cardiovascular health: the razor-sharp double-edged sword. J Am Coll Cardiol. 2007 Sep 11;50(11):1009-14.

42. Di Castelnuovo A, Rotondo S, Iacoviello L, Donati MB, De Gaetano G. Meta-analysis of wine and beer consumption in relation to vascular risk. Circulation. 2002 Jun $18 ; 105(24): 2836-44$.

43. Rimm EB, Klatsky A, Grobbee D, Stampfer MJ. Review of moderate alcohol consumption and reduced risk of coronary heart disease: is the effect due to beer, wine, or spirits. BMJ. 1996 Mar 23;312(7033):731-6. 
Table 1. Age-standardized ${ }^{\mathrm{a}}$ baseline characteristics according to alcohol intake among women in the Swedish Women's Lifestyle and Health Study (Aug 1991 - Jun 1992)

Total Alcohol Intake (g/day)

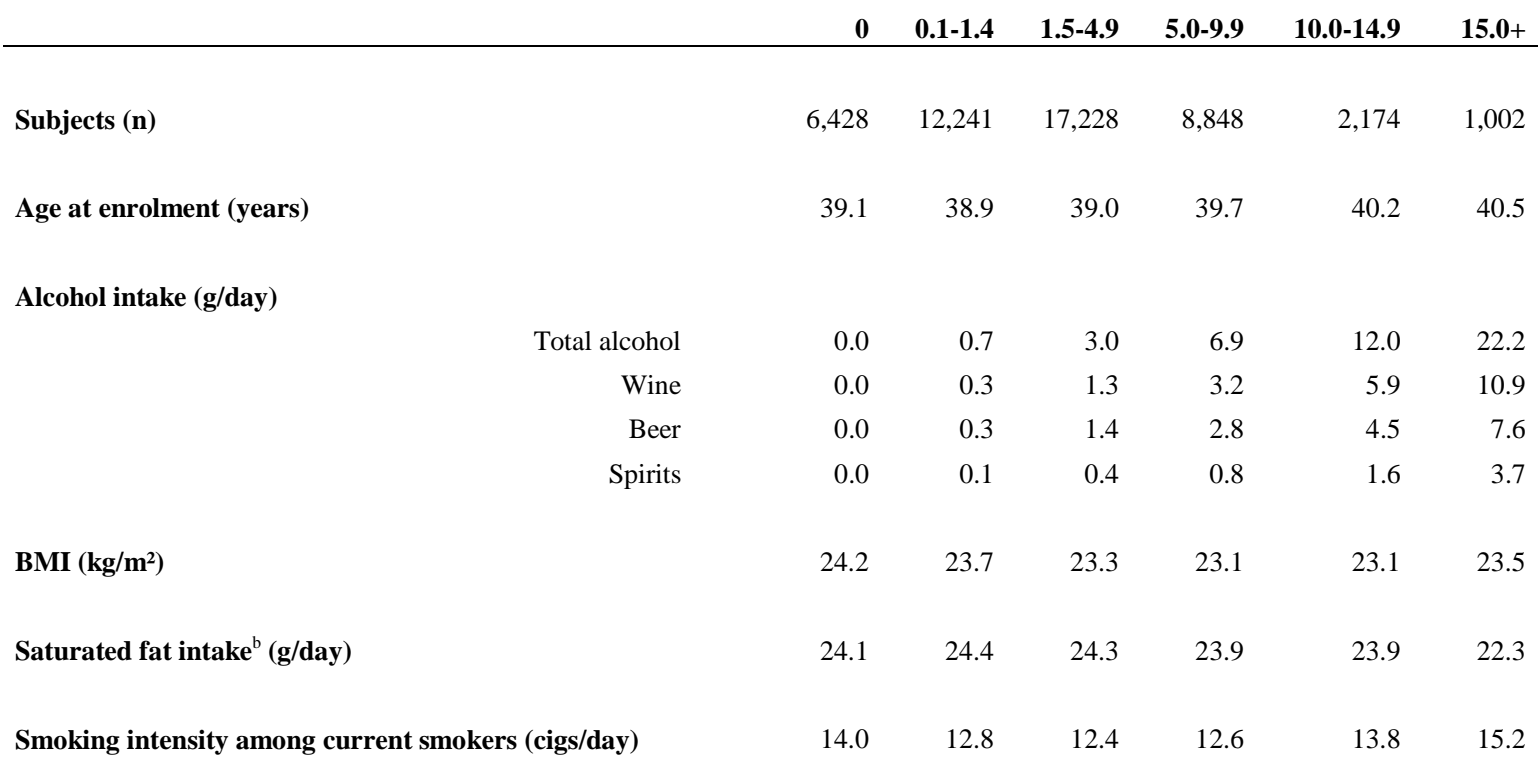

Smoking status (\%)

$\begin{array}{rllllll}\text { Never } & 50 & 47 & 41 & 32 & 26 & 17 \\ \text { Past } & 23 & 27 & 32 & 35 & 35 & 34 \\ \text { Current } & 26 & 26 & 28 & 33 & 39 & 49\end{array}$

History of prevalent disease $(\%)$

$\begin{array}{rrrrrrr}\text { Hypertension } & 11 & 9 & 9 & 8 & 9 & 10 \\ \text { Diabetes } & 2 & 1 & 1 & 1 & 1 & 1\end{array}$

Physical activity (\%)

$\begin{array}{rllllll}\text { Low } & 18 & 15 & 13 & 14 & 16 & 23 \\ \text { Intermediate } & 64 & 62 & 59 & 57 & 56 & 53 \\ \text { High } & 19 & 23 & 27 & 28 & 28 & 24\end{array}$

Years of education ${ }^{\mathrm{c}}(\%)$

$\begin{array}{rllllll}0-10 & 41 & 32 & 27 & 25 & 26 & 25 \\ 11-13 & 36 & 40 & 41 & 39 & 36 & 36 \\ 14+ & 23 & 28 & 32 & 37 & 38 & 39\end{array}$

\footnotetext{
${ }^{a}$ Using direct standardization to the baseline age distribution of the cohort

${ }^{\mathrm{b}}$ Energy-adjusted with the residual method (Willett 1997)

${ }^{\mathrm{c}}$ Ten years of education correspond to completion of compulsory school; 13 years of education correspond to completion of secondary school; 14 years of education or more correspond to graduate study at a university.
} 


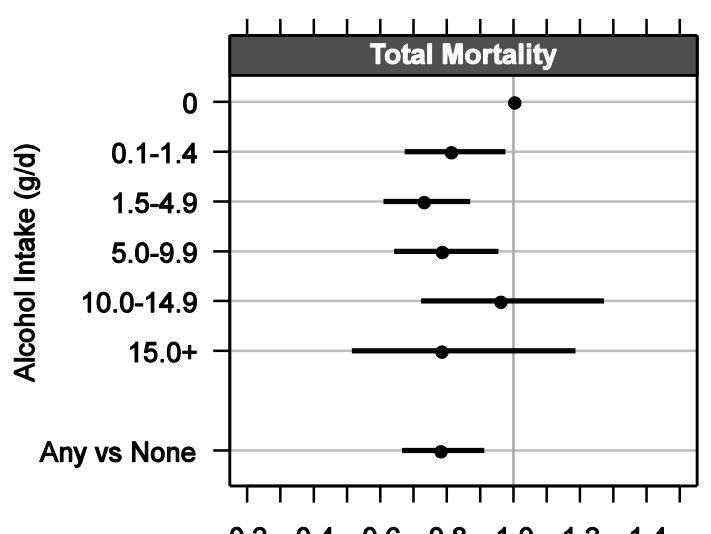

$\begin{array}{lllllll}0.2 & 0.4 & 0.6 & 0.8 & 1.0 & 1.2 & 1.4\end{array}$

Age-adjusted Relative Risk

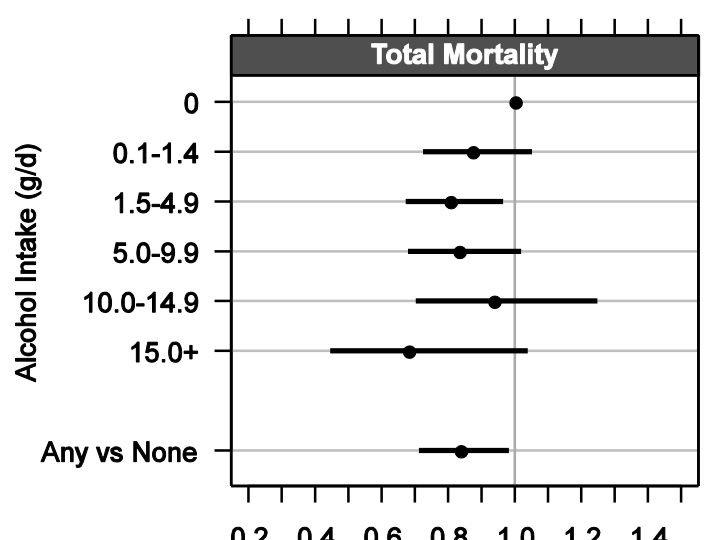

Multivariable-adjusted Relative Risk

Fig 1. Relative Risk of Mortality from any Cause in Relation to Average Daily Total Alcohol Intake Among Swedish Women: The Swedish Women's Lifestyle and Health Study, 1991-2006. The age-adjusted relative risks were: RR for zero alcohol intake=1 (ref.); RR for 0.1-1.4 grams per day $=0.81 ; 95 \% \mathrm{CI}=0.67-0.98$; RR for $1.5-4.9$ grams per day=0.73; $95 \% \mathrm{CI}=0.61-0.87$; RR for $5.0-9.9$ grams per day=0.78; $95 \%$ $\mathrm{CI}=0.64-0.95$; RR for 10.0-14.9 grams per day=0.96; $95 \% \mathrm{CI}=0.72-1.27$; RR for $15.0+$ grams per day=0.78; $95 \% \mathrm{CI}=0.51-1.19$; $\mathrm{RR}$ for any alcohol intake=0.78; 95\% CI=0.66-0.91. The multivariable-adjusted relative risks were: $\mathrm{RR}$ for zero alcohol intake=1 (ref.); $\mathrm{RR}$ for $0.1-1.4$ grams per day=0.87; $95 \% \mathrm{CI}=0.72-1.05 ; \mathrm{RR}$ for $1.5-4.9$ grams per day=0.81; $95 \% \mathrm{CI}=0.67-0.97$; RR for $5.0-9.9$ grams per day=0.83; $95 \%$ $\mathrm{CI}=0.67-1.01$; RR for 10.0-14.9 grams per day=0.94; $95 \% \mathrm{CI}=0.70-1.25$; RR for $15.0+$ grams per day=0.68; $95 \% \mathrm{CI}=0.45-1.04 ; \mathrm{RR}$ for any alcohol intake=0.84; 95\% CI=0.71-0.98. Multivariable-adjusted relative risks were adjusted for age $(5$-year categories $)$, BMI $(<18.5,18.5$ $24.9,25.0+\mathrm{kg} / \mathrm{m}^{2}$ ), energy-adjusted saturated fat intake (quintiles), smoking status (never, past, and current smoking with current intensities of 1-14 cigs/day, 15-24 cigs/day, and 25+ cigs/day), current physical activity (low, intermediate, high), years of education (0-10, 11-13, 14+ years, where ten years of education correspond to completion of compulsory school, 13 years of education correspond to completion of secondary school, and 14 years of education or more correspond to graduate study at university). 
Table 2. Relative Risk of Cause-specific Mortality in Relation to Average Daily Total Alcohol Intake Among Swedish Women: The Swedish Women's Lifestyle and Health Study, 1991-2006.

\begin{tabular}{|c|c|c|c|c|c|c|c|}
\hline \multirow[b]{2}{*}{ Cause-specific Mortality } & \multirow[b]{2}{*}{ Total Alcohol Intake (g/day) } & \multirow[b]{2}{*}{ Cases } & \multirow{2}{*}{$\begin{array}{l}\text { Person- } \\
\text { years }\end{array}$} & \multicolumn{4}{|c|}{ Relative Risk $(95 \% \text { CI })^{a}$} \\
\hline & & & & & e-adjusted & Mu & Itivariable-adjusted ${ }^{\mathrm{b}}$ \\
\hline \multirow[t]{8}{*}{ Cancer-related } & 0 & 101 & 95,232 & 1.00 & (ref.) & 1.00 & (ref.) \\
\hline & $0.1-1.4$ & 179 & 182,521 & 0.94 & $(0.74-1.20)$ & 0.99 & $(0.78-1.27)$ \\
\hline & $1.5-4.9$ & 227 & 257,081 & 0.85 & $(0.67-1.07)$ & 0.91 & $(0.72-1.16)$ \\
\hline & $5.0-9.9$ & 116 & 131,392 & 0.80 & $(0.61-1.04)$ & 0.84 & $(0.64-1.10)$ \\
\hline & $10.0+$ & 50 & 47,069 & 0.90 & $(0.64-1.27)$ & 0.87 & $(0.62-1.23)$ \\
\hline & p-trend & & & 0.13 & & 0.07 & \\
\hline & $0.1-19.9$ (compared to none) & 567 & 612,315 & 0.87 & $(0.70-1.07)$ & 0.92 & $(0.75-1.15)$ \\
\hline & Any (compared to none) & 572 & 618,063 & 0.87 & $(0.70-1.07)$ & 0.92 & $(0.74-1.14)$ \\
\hline \multirow[t]{8}{*}{ CVD-related } & 0 & 33 & 95,232 & 1.00 & (ref.) & 1.00 & (ref.) \\
\hline & $0.1-1.4$ & 41 & 182,521 & 0.66 & $(0.42-1.04)$ & 0.76 & $(0.48-1.20)$ \\
\hline & $1.5-4.9$ & 40 & 257,081 & 0.46 & $(0.29-0.73)$ & 0.57 & $(0.36-0.91)$ \\
\hline & $5.0-9.9$ & 34 & 131,392 & 0.71 & $(0.44-1.15)$ & 0.85 & $(0.52-1.38)$ \\
\hline & $10.0+$ & 10 & 47,069 & 0.55 & $(0.27-1.12)$ & 0.55 & $(0.27-1.12)$ \\
\hline & p-trend & & & 0.30 & & 0.26 & \\
\hline & 0.1-19.9 (compared to none) & 123 & 612,315 & 0.58 & $(0.39-0.85)$ & 0.69 & $(0.46-1.01)$ \\
\hline & Any (compared to none) & 125 & 618,063 & 0.58 & $(0.40-0.85)$ & 0.69 & $(0.46-1.01)$ \\
\hline \multirow{9}{*}{$\begin{array}{l}\text { Neither cancer- nor CVD- } \\
\text { related }\end{array}$} & & & & & & & \\
\hline & 0 & 50 & 95,232 & 1.00 & (ref.) & 1.00 & (ref.) \\
\hline & $0.1-1.4$ & 62 & 182,521 & 0.65 & $(0.45-0.95)$ & 0.70 & $(0.48-1.02)$ \\
\hline & $1.5-4.9$ & 89 & 257,081 & 0.67 & $(0.47-0.94)$ & 0.72 & $(0.51-1.03)$ \\
\hline & $5.0-9.9$ & 57 & 131,392 & 0.80 & $(0.55-1.18)$ & 0.82 & $(0.55-1.20)$ \\
\hline & $10.0+$ & 30 & 47,069 & 1.14 & $(0.73-1.80)$ & 0.98 & $(0.62-1.57)$ \\
\hline & p-trend & & & 0.03 & & 0.24 & \\
\hline & 0.1-19.9 (compared to none) & 230 & 612,315 & 0.71 & $(0.53-0.97)$ & 0.75 & $(0.55-1.02)$ \\
\hline & Any (compared to none) & 238 & 618,063 & 0.73 & $(0.54-0.99)$ & 0.76 & $(0.56-1.03)$ \\
\hline
\end{tabular}

${ }^{\mathrm{a}} \mathrm{CI}=$ confidence interval

${ }^{\mathrm{b}}$ Adjusted for age (5-year categories), BMI ( $\left.<18.5,18.5-24.9,25.0+\mathrm{kg} / \mathrm{m}^{2}\right)$, energy-adjusted saturated fat intake (quintiles), smoking status (never, past, and current smoking with current intensities of 1-14 cigs/day, 15-24 cigs/day, and 25+ cigs/day), current physical activity (low, intermediate, high), years of education $(0-10,11-13,14+$ years, where ten years of education correspond to completion of compulsory school, 13 years of education correspond to completion of secondary school, and 14 years of education or more correspond to graduate study at university). 
Table 3. Multivariable Relative Risks of Total Mortality in Relation to Average Daily Total Alcohol Intake, Stratified by Age, Among Swedish Women: The Swedish Women's Lifestyle and Health Study, 1991-2006.

Stratum Total Alcohol Intake (g/day) Cases $\quad$ Person-years $\quad \begin{gathered}\text { Multivariable-adjusted } \\ \text { Relative Risk (95\% CI) }{ }^{a}\end{gathered}$

Age at enrolment (years)

$\begin{array}{rrrrl}30-34 & 0 & 17 & 27,596 & 1.00 \text { (ref.) } \\ 0.1-1.4 & 44 & 52,939 & 1.51(0.86-2.64) \\ 1.5-4.9 & 45 & 69,829 & 1.24(0.70-2.18) \\ 5.0-9.9 & 18 & 29,652 & 1.16(0.59-2.27) \\ 10.0-14.9 & 3 & 6,407 & 0.81(0.23-2.77) \\ 15.0+ & 6 & 2,570 & 3.11(1.18-8.20) \\ 35-49 & & & & \\ & 0.1-1.4 & 238 & 129,582 & 0.81(0.67-0.99) \\ 1.5-4.9 & 311 & 187,252 & 0.76(0.63-0.92) \\ & 5.0-9.9 & 189 & 101,740 & 0.82(0.66-1.01) \\ 10.0-14.9 & 62 & 25,799 & 0.98(0.73-1.31) \\ 15.0+ & 19 & 12,292 & 0.55 \text { (0.34-0.90) }\end{array}$

\footnotetext{
${ }^{\text {a }} \mathrm{CI}=$ confidence interval; relative risks adjusted for age (5-year categories), BMI $\left(<18.5,18.5-24.9,25.0+\mathrm{kg} / \mathrm{m}^{2}\right)$, energy-adjusted saturated fat intake (quintiles), smoking status (never, past, and current smoking with current intensities of 1-14 cigs/day, 15-24 cigs/day, and 25+ cigs/day), current physical activity (low, intermediate, high), years of education (0-10, 11-13, 14+ years, where ten years of education correspond to completion of compulsory school, 13 years of education correspond to completion of secondary school, and 14 years of education or more correspond to graduate study at university).
} 
Table 4. Relative Risk of Mortality from any Cause in Relation to Average Daily Beverage-type-specific Alcohol Intake Among Swedish Women: The Swedish Women's Lifestyle and Health Study, 1991-2006.

Relative Risk $(95 \% \text { CI })^{\text {a }}$ Alcohol intake (g/day) Cases Person-years Multivariable-adjusted ${ }^{c}$

Wine

$\begin{array}{rrrrlll}0 & 388 & 205,488 & 1.00 & (\text { ref. }) & 1.00 & \text { (ref.) } \\ 0.1-1.4 & 389 & 283,554 & 0.83 & (0.71-0.97) & 0.91 & (0.78-1.06) \\ 1.5-4.9 & 223 & 156,447 & 0.79 & (0.66-0.94) & 0.88 & (0.74-1.06) \\ 5.0+ & 119 & 67,805 & 0.82 & (0.66-1.01) & 0.85 & (0.69-1.06) \\ \text { p-trend } & & & 0.07 & & 0.18 & \end{array}$

Beer

$\begin{array}{rrrrlll}0 & 393 & 199,366 & 1.00 & \text { (ref.) } & 1.00 & \text { (ref.) } \\ 0.1-1.4 & 396 & 276,444 & 0.76 & (0.65-0.88) & 0.83 & (0.72-0.96) \\ 1.5-4.9 & 268 & 193,921 & 0.74 & (0.63-0.88) & 0.83 & (0.70-0.98) \\ 5.0+ & 62 & 43,564 & 0.77 & (0.59-1.02) & 0.79 & (0.60-1.05) \\ \text { p-trend } & & & 0.03 & & 0.09 & \end{array}$

Spirits

$\begin{array}{rrrllll}0 & 593 & 382,916 & 1.00 & (\text { ref. }) & 1.00 & \text { (ref.) } \\ 0.1-1.4 & 367 & 258,610 & 1.06 & (0.91-1.22) & 0.98 & (0.85-1.13) \\ 1.5-4.9 & 129 & 64,102 & 1.32 & (1.08-1.60) & 1.09 & (0.89-1.33) \\ 5.0+ & 30 & 7,667 & 2.27 & (1.56-3.29) & 1.52 & (1.04-2.22) \\ \text { p-trend } & & & <0.0001 & 0.05 & \end{array}$

\footnotetext{
${ }^{\mathrm{a}} \mathrm{CI}=$ confidence interval

b The alcohol-type specific analyses (wine/beer/spirits) in grams of alcohol per day are additionally adjusted for the intake of complementary alcohol types $(0,0.1-1.4,1.5-4.9,5.0+$ grams/day), e.g. the wine analysis is adjusted for beer and for spirits intakes, while the alcohol-type specific analyses (wine/beer/spirits) in per cent of total alcohol intake are additionally adjusted for the level of total alcohol intake $(0,0.1-1.4,1.5-4.9,5.0-9.9,10.0-14.9,15+$ grams/day).

${ }^{\mathrm{c}}$ Adjusted for age (5-year categories), BMI (<18.5, 18.5-24.9, 25.0+ kg/m²), energy-adjusted saturated fat intake (quintiles), smoking status (never, past, and current smoking with current intensities of 1-14 cigs/day, 15-24 cigs/day, and 25+ cigs/day), current physical activity (low, intermediate, high), years of education (0-10,11-13, 14+ years, where ten years of education correspond to completion of compulsory school, 13 years of education correspond to completion of secondary school, and 14 years of education or more correspond to graduate study at university). The alcohol-type specific analyses (wine/beer/spirits) in grams of alcohol per day are additionally adjusted for the intake of complementary alcohol types $(0,0.1-1.4,1.5-4.9,5.0+$ grams/day), e.g. the wine analysis is adjusted for beer and for spirits intakes.
} 